\title{
Thymidylate synthase polymorphisms and mRNA expression are independent chemotherapy predictive markers in esophageal adenocarcinoma patients
}

\author{
HIDEKAZU KURAMOCHI ${ }^{1,5}$, KOJI TANAKA ${ }^{1}$, DANIEL OH ${ }^{2}$, BETHANY J. LEHMAN ${ }^{2}$, CHRISTY M. DUNST $^{2}$, \\ DONG YUN YANG ${ }^{3}$, STEVEN R. DE MEESTER ${ }^{2}$, JEFFERY A. HAGEN ${ }^{2}$, KATHLEEN D. DANENBERG $^{4}$, \\ TOM R. DE MEESTER ${ }^{2}$ and PETER V. DANENBERG ${ }^{1}$
}

\begin{abstract}
Departments of ${ }^{1}$ Biochemistry and Molecular Biology, ${ }^{2}$ Surgery, and ${ }^{3}$ Norris Comprehensive Cancer Center, University of Southern California, 1441 East Lake Avenue, Los Angeles, CA 90033; ${ }^{4}$ Response Genetics Inc., 1640 Marengo Street, HRA building 620, Los Angeles, CA 90033, USA; ${ }^{5}$ Department of Gastroenterology,

Tokyo Women's Medical University, 8-1 Kawadacho, Shinjukuku, Tokyo 162-8666, Japan
\end{abstract}

Received August 20, 2007; Accepted October 19, 2007

\begin{abstract}
Thymidylate synthase (TS) is known to have polymorphisms in the 5' and $3^{\prime}$ untranslated region (UTR). These polymorphisms have been reported to be associated with high TS expression and chemoresistance to 5-FU. The aim of this study was to examine the prognostic roles of the 5'-UTR and 3'-UTR TS polymorphisms in esophageal adenocarcinoma patients, as well as their relation with TS mRNA expression. Eighty-three patients with esophageal adenocarcinoma were assessed. Thirty-four had received 5-FU containing chemotherapy and 49 were treated with surgery alone. Surgically resected tumor tissues were analyzed for TS genotype and TS mRNA expression using a quantitative real-time RT-PCR method. No survival difference was seen between the patients with $3 R G$ allele (3RG group) and non-3RG group among surgery-alone patients. However, among patients with a history of 5-FUbased chemotherapy, the non-3RG group showed significantly better overall survival compared to the $3 \mathrm{RG}$ group $(\mathrm{p}=0.02)$. Moreover, whereas chemotherapy produced a significant increase in survival for the non-3RG group patients, those in the 3RG group obtained no survival benefit from chemotherapy. When patients were classified by low or high TS mRNA expression levels, low TS expressers obtained survival benefit from chemotherapy while high TS expressers did not, although there was no difference of median TS mRNA levels between 3RG and non-3RG group. The 3'-UTR polymorphism was not associated with overall survival. These
\end{abstract}

Correspondence to: Dr Peter V. Danenberg, Norris Comprehensive Cancer Center/University of Southern California, NOR 5318, 1441 Eastlake Avenue, Los Angeles, CA 90033, USA

E-mail: pdanenbe@usc.edu

Key words: thymidylate synthase, polymorphism, gene expression, chemotherapy, esophageal adenocarcinoma results suggest that the status of the TS 5'-UTR polymorphism and TS mRNA expression are independent predictive markers for survival benefit from 5-FU-based therapy.

\section{Introduction}

Esophageal adenocarcinoma is one of the fastest rising cancers in the Western countries, the incidence of which has increased dramatically in USA (1). Even for those who underwent a curative surgical resection, 5-year survival rates remain very low, ranging from 20 to $40 \%(2,3)$. Therefore combined modality treatment approaches, such as systemic chemotherapy, are necessary for those patients. Fluorouracil has been used in the treatment of gastrointestinal cancer and still remains the cornerstone for esophageal adenocarcinoma (4). The primary mechanism of action of fluorouracil is the inhibition of the DNA-synthetic enzyme thymidylate synthase (TS). In several studies, TS expression has been reported to be associated with response to 5-fluorouracil (5-FU) therapy and prognosis; with high TS levels in most cases associated with poorer response and survival (5-8).

TS gene is known to have several polymorphisms in its $5^{\prime}$ untranslated region (UTR) and 3'-UTR. The first studied polymorphism is a tandem repeat sequence in 5'-UTR, which consists of either two or three 28-bp repeated sequences (9). The triple repeat (3R) allele has been associated with high TS mRNA and/or protein expression, and patients with a homozygous $3 \mathrm{R}$ genotype have generally shown less response to 5-FU related chemotherapy and poorer survival when compared to the patients with the homozygous double repeat (2R) genotype (10-13). In addition, a G/C single nucleotide polymorphism (SNP) within the $3 R$ allele segregates the $3 R$ allele into $3 \mathrm{RG}$ and $3 \mathrm{RC}(14,15)$. The 3RC allele apparently can abolish the increased transcriptional activity of the $3 \mathrm{R}$ variant in vitro, by altering a transcription factor-binding site (15). Another polymorphism, a 6-bp insertion/deletion (ins/del) in the 3'-UTR (16) has been associated with TS mRNA stability in vitro, and intratumoral TS mRNA 
Table I. Patient characteristics.

\begin{tabular}{|c|c|c|c|c|c|c|c|c|c|}
\hline & \multicolumn{2}{|c|}{ 5'-UTR genotype } & \multirow[b]{2}{*}{$\mathrm{P}$-value } & \multicolumn{2}{|c|}{ 3'UTR genotype } & \multirow[b]{2}{*}{ P-value } & \multicolumn{2}{|c|}{ TS mRNA levels } & \multirow[b]{2}{*}{ P-value } \\
\hline & $\begin{array}{c}3 \mathrm{RG} \\
\text { group } \\
(\mathrm{n}=30)\end{array}$ & $\begin{array}{l}\text { Non-3RG } \\
\text { group } \\
(\mathrm{n}=52)\end{array}$ & & $\begin{array}{l}\text { ins/ins } \\
(n=28)\end{array}$ & $\begin{array}{l}\text { ins/del, } \\
\text { del/del } \\
(n=52)\end{array}$ & & $\begin{array}{l}\text { High } \\
(>2.79) \\
(n=44)\end{array}$ & $\begin{array}{c}\text { Low } \\
(\leq 2.79) \\
(n=33)\end{array}$ & \\
\hline \multicolumn{10}{|l|}{ Age (years) } \\
\hline$\leq 65$ & 12 & 27 & \multirow[t]{2}{*}{0.36} & 15 & 23 & \multirow[t]{2}{*}{0.49} & 22 & 15 & \multirow[t]{2}{*}{0.69} \\
\hline$>65$ & 18 & 25 & & 13 & 29 & & 22 & 18 & \\
\hline \multicolumn{10}{|l|}{ Gender } \\
\hline Male & 24 & 41 & \multirow[t]{2}{*}{1.00} & 24 & 39 & \multirow[t]{2}{*}{0.39} & 33 & 27 & \multirow[t]{2}{*}{0.48} \\
\hline Female & 6 & 11 & & 4 & 13 & & 11 & 6 & \\
\hline \multicolumn{10}{|l|}{ Histotype } \\
\hline Moderate & 10 & 26 & \multirow[t]{2}{*}{0.17} & 12 & 22 & \multirow[t]{2}{*}{1.00} & 23 & 13 & \multirow[t]{2}{*}{0.32} \\
\hline Poor & 19 & 25 & & 15 & 29 & & 21 & 19 & \\
\hline \multicolumn{10}{|l|}{ Stage } \\
\hline I & 2 & 2 & \multirow{4}{*}{0.65} & 2 & 1 & \multirow{4}{*}{0.37} & 1 & 2 & \multirow{4}{*}{0.53} \\
\hline II & 6 & 15 & & 9 & 11 & & 14 & 6 & \\
\hline III & 19 & 32 & & 15 & 36 & & 26 & 22 & \\
\hline IV & 3 & 3 & & 2 & 4 & & 3 & 3 & \\
\hline \multicolumn{10}{|l|}{ Chemo status } \\
\hline Never & 17 & 31 & \multirow{5}{*}{0.54} & 15 & 31 & & 26 & 22 & \multirow{5}{*}{0.88} \\
\hline Adjuvant & 7 & 9 & & 6 & 10 & & 9 & 6 & \\
\hline Reccurence & 3 & 9 & & 4 & 8 & 0.77 & 7 & 4 & \\
\hline Adjuvant and rec & 1 & 2 & & 2 & 1 & & 2 & 1 & \\
\hline Neoadjuvant & 2 & 1 & & 1 & 2 & & Excluded & & \\
\hline \multicolumn{10}{|l|}{ TS mRNA levels } \\
\hline High (>2.79) & 15 & 29 & \multirow[t]{2}{*}{0.63} & 15 & 28 & \multirow[t]{2}{*}{0.74} & & & \\
\hline Low $(\leq 2.79)$ & 13 & 20 & & 10 & 22 & & & & \\
\hline
\end{tabular}

3RG group, 2R/3RG, 3RC/3RG, 3RG/3RG; non-3RG group, 2R/2R, 2R/3RC, 3RC/3RC; P-value, Fisher's exact test.

expression in vivo (17). Some previous studies reported finding an association between the 3'-UTR polymorphism and prognosis of cancer patients $(18,19)$ while others reported no associations (20-22).

The aim of this study was to examine the prognostic and predictive roles of the 5'-UTR and 3'-UTR polymorphisms in esophageal adenocarcinoma patients, as well as their relation with TS mRNA expression.

\section{Materials and methods}

Patient characteristics. Eighty-two patients with esophageal adenocarcinoma who underwent esophagectomy in University of Southern California hospital between 1992 and 2004 were assessed. Written informed consent was obtained from every patient according to the institutional regulations. Patient characteristics are listed in Table I. Thirty-four patients had received 5-FU-based chemotherapy during their treatment period (16 patients with adjuvant chemotherapy, 12 patients with chemotherapy upon recurrence, 3 patients with both adjuvant and upon recurrence, and 3 patients with neoadjuvant therapy), and 48 patients had never received 5-FU.

Microdissection. Formalin-fixed paraffin embedded (FFPE) tumor specimens were obtained from surgically-resected blocks. FFPE specimens were cut into serial sections with a thickness of $10 \mu \mathrm{m}$. For the pathological diagnosis, one slide was stained with $H \& E$ and evaluated by pathologist. Other sections were stained with nuclear fast red (NFR, 
American MasterTech Scientific Inc., Lodi, CA) to enable visualization of histology. Laser capture microdissection (P.A.L.M. Microlaser Technologies AG, Munich, Germany) was performed in all the tumor samples to ensure that only tumor cells were dissected. Adjacent normal esophageal mucosa was dissected from the slide using a scalpel.

RNA extraction from FFPE samples. Extraction of RNA from FFPE tumor specimens and adjacent non-cancerous tissues was performed as described previously (23). After RNA isolation, cDNA was prepared from each sample as described previously (24).

Genomic DNA extraction. After the aqueous phase was removed for RNA extraction in the procedure above, $300 \mu 1$ of GITC/Sarc solution and $150 \mu \mathrm{l}$ of $1 \mathrm{M}$ Tris- $\mathrm{HCl}(\mathrm{pH} 8.0)$ (Invitrogen, Carlsbad, CA) were added into the remained organic phase, followed by $600 \mu 1$ of pre-mixed phenol/ chloroform/isoamyl alcohol ( $\mathrm{pH}$ 8.05-8.35) (Invitrogen). The tubes were voltexed for $15 \mathrm{sec}$, placed on ice for $15 \mathrm{~min}$, and then centrifuged at $13,000 \mathrm{rpm}$ for $8 \mathrm{~min}$ in a chilled $\left(8^{\circ} \mathrm{C}\right)$ centrifuge. The upper aqueous phase $(800-1000 \mu \mathrm{l})$ was carefully removed and placed in a $2-\mu 1$ tube. Glycogen $(10 \mu 1)$ and $1000 \mu 1$ of isopropanol were added and the samples were vortexed for $10-15 \mathrm{sec}$. The tubes were placed at $-20^{\circ} \mathrm{C}$ for $30-45 \mathrm{~min}$ to precipitate the DNA. The samples were then centrifuged at $13,000 \mathrm{rpm}$ for $7 \mathrm{~min}$ in a chilled $\left(8^{\circ} \mathrm{C}\right)$ centrifuge. The supernatant was poured off and $500 \mu 1$ of $75 \%$ ethanol was added. The tubes were centrifuged at $13,000 \mathrm{rpm}$ for $6 \mathrm{~min}$ in a chilled $\left(8^{\circ} \mathrm{C}\right)$ centrifuge. The supernatant was carefully poured off so as not to disturb the DNA pellet and the samples were quick-spun for $15 \mathrm{sec}$ at $13,000 \mathrm{rpm}$. The remaining ethanol was removed with a $20 \mu 1$ pipette and the samples air-dried for $15 \mathrm{~min}$. The pellet was re-suspended in $50 \mu 1$ of $5 \mathrm{mM}$ Tris.

Real-time PCR quantification of mRNA expression. Quantitation of TS mRNA and an internal reference gene (ß-actin) was done using a fluorescence based real-time detection method [ABI PRISM 7900 Sequence detection System (TaqMan ${ }^{\circledR}$ ) Perkin-Elmer (PE) Applied Biosystem, Foster City, CA, USA], as described previously (25). The sequence of primers and probes of TS and $B$-actin were previously described (25).

Gene expression values (relative mRNA levels) are expressed as ratios (differences between the $\mathrm{Ct}$ values) between the genes of interest (TS in this case) and an internal reference gene ( $\beta$-actin) that provides a normalization factor for the amount of RNA isolated from a specimen.

Evaluation of TS polymorphisms. The promoter region of the TS gene in 5'-UTR was amplified by PCR using the primers and PCR conditions described previously (13). The number of tandem repeats was analyzed by Agilent 2100 bioanalyzer and DNA 500 Assay kit (Agilent Technologies Inc., Palo Alto, CA). A G/C polymorphism in triple repeat sequence was analyzed as described previously (14). A 6-bp insertion/ deletion polymorphism in 3'-UTR region was analyzed as previously described (16). Since the genotype from cancer tissue and that from non-cancerous tissue are not always the same in case of loss of heterozygosity $(\mathrm{LOH})(13,14)$ adjacent non-cancerous esophageal mucosa was also assessed, and the genotype from non-cancerous tissue was compared to the genotype from cancer tissue in each patient.

Statistical analysis. Overall survival was measured from the date of surgery to the date of death (any cause) or the date last seen. Survival curves were generated using the KaplanMeier method. The log-rank statistic was used to compare survival distributions. Fisher's exact test was used for comparison of patient characteristics, and for assessing linkage disequilibrium between 5'-UTR and 3'-UTR polymorphism. The Mann-Whitney U test was used to compare the median TS mRNA values between groups. The maximal $\chi^{2}$ method of Miller and Siegmund and Halpern was adapted to determine which TS gene expression value (optimal cut point) best segregated patients into poor- and good-prognosis subgroups (in terms of likelihood of survival). The Cox proportional hazards model was used to assess the prognostic importance of parameters. All reported P-values are two-sided and statistical significance was set at the 0.05 level for the P-value.

\section{Results}

The distribution of 5'-UTR genotype and 3'-UTR genotype. We followed the convention established by previous studies and classified the 5'-UTR genotypes into the $3 \mathrm{RG}$ group $(2 \mathrm{R} / 3 \mathrm{RG}, 3 \mathrm{RC} / 3 \mathrm{RG}, 3 \mathrm{RG} / 3 \mathrm{RG})$ and the non-3RG group $(2 \mathrm{R} / 2 \mathrm{R}, 2 \mathrm{R} / 3 \mathrm{RC}, 3 \mathrm{RC}, 3 \mathrm{RC})$, while the 3'-UTR genotypes were classified into the Ins group (ins/ins) and Del group (ins/del, del/del) $(17,26,27)$. Significant linkage disequilibrium was observed between two polymorphism groups $(\mathrm{p}=0.002)$. Whereas the Del genotype was distributed evenly between the $3 R G$ and non-3RG genotypes, the Ins genotype was predominantly associated with the non-3RG group.

Frequency of LOH in 5'-UTR locus. The 5'-UTR genotype was compared between cancer and non-cancerous (normal) tissue in order to evaluate LOH in this locus. Among 39 patients with informative heterozygous 5'-UTR genotype in their normal tissue, 17 patients showed LOH in their cancer tissue $(43.6 \%)$. In 3 of these patients, the $\mathrm{LOH}$ led to an absence of the $3 \mathrm{G}$ allele in their cancer tissue, and thus a genotype discrepancy between cancer and normal tissue in the 5 ' UTR region $(3 / 39=7.7 \%)$.

TS 5'-UTR genotype and prognosis. In the entire set of patients, those in the non-3RG group showed significantly better overall survival compared to patients in the $3 \mathrm{RG}$ group $(\mathrm{p}=0.038)$. Among the patients who had received 5-FU related chemotherapy (5-FU(+) patients), a survival difference was observed between the $3 R G$ and the non-3RG groups ( $\mathrm{p}=0.018)$ (Fig. 1B). However, among the patients who had never received 5-FU related chemotherapy (5-FU(-) patients), no significant survival difference was seen between these 2 groups ( $\mathrm{p}=0.34$ ) (Fig. 1A). Overall survival in $5-\mathrm{FU}(+)$ patients was significantly longer than $5-\mathrm{FU}(-)$ patients in the non-3RG group $(\mathrm{p}=0.0180)$, while no significant difference 

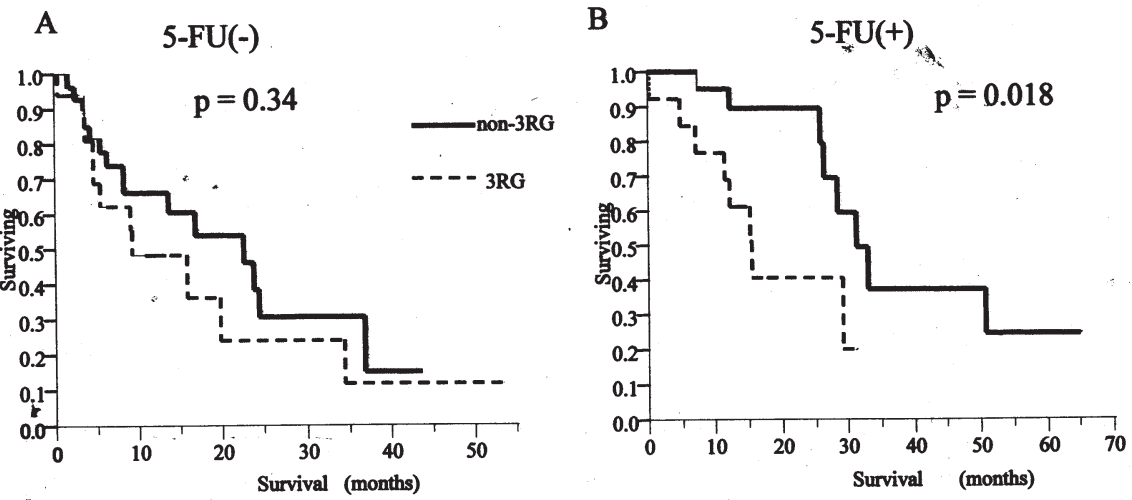

Figure 1. Kaplan-Meier analysis of overall survival in patients with esophageal adenocarcinoma according to TS 5'-UTR polymorphism. (A) In the patients who had received 5-FU related chemotherapy. (B) In the patients who had never received 5-FU.
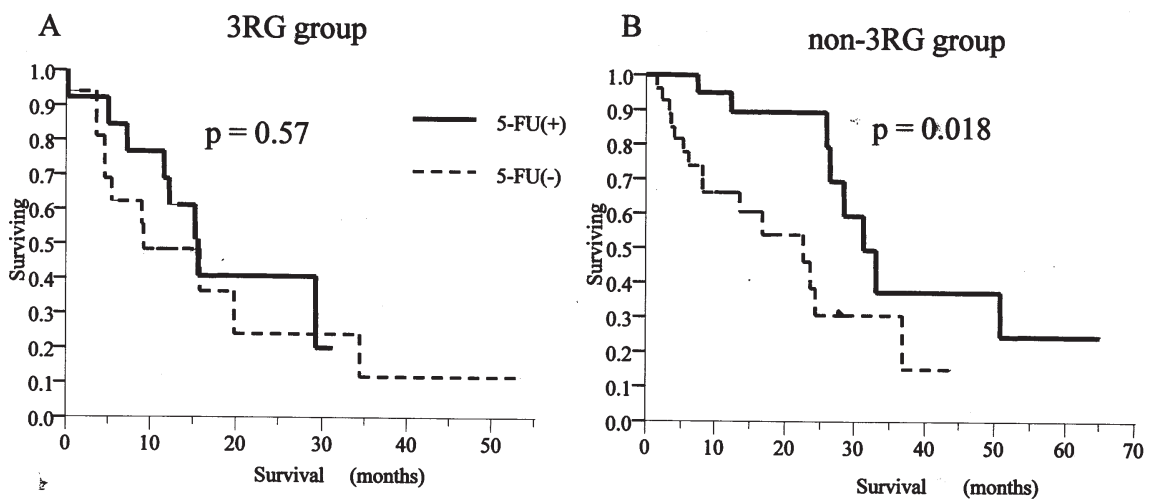

Figure 2. Kaplan-Meier analysis of overall survival in patients with esophageal adenocarcinoma according to a history of 5-FU treatment. (A) In patients who had at least one 3RG allele. (B) In the patients who did not have a 3RG allele.

Table II. TS mRNA levels in each genotypes.

\begin{tabular}{|c|c|c|c|c|c|c|}
\hline & \multicolumn{2}{|c|}{ 5'-UTR genotype } & \multirow[b]{2}{*}{ P-value } & \multicolumn{2}{|c|}{ 3'-UTR genotype } & \multirow[b]{2}{*}{ P-value } \\
\hline & 3RG group & Non-3RG group & & ins/ins & ins/del, del/del & \\
\hline Cancer & $3.62(1.01-32.16)$ & $3.34(0.80-19.54)$ & 0.73 & $3.23(0.8-19.54)$ & $3.48(1.14-32.16)$ & 0.94 \\
\hline Normal & $1.79(0.77-3.51)$ & $1.59(0.34-4.61)$ & 0.40 & $1.85(0.34-3.28)$ & $1.62(0.77-4.61)$ & 0.33 \\
\hline
\end{tabular}

TS mRNA, median (range); 3RG group, 2R/3RG, 3RC/3RG, 3RG/3RG; non-3RG group, 2R/2R, 2R/3RC, 3RC/3RC; p-value, Mann-Whitney U test.

was observed between survival of 5-FU(+) patients and 5-FU(-) patients in the $3 R G$ group ( $\mathrm{p}=0.57$ ) (Fig. 2).

TS mRNA expression level and genotypes. The patients who had received neoadjuvant chemotherapy were excluded from assessing TS mRNA expression because mRNA levels might be changed after chemotherapy. TS mRNA expression levels were assessable in 77 patients. No significant difference was found between median TS mRNA expression levels of the $3 R G$ and the non-3RG groups in either cancer tissue $(p=0.73)$ or in normal tissue $(\mathrm{p}=0.40)$. Likewise, no difference was observed between median TS mRNA levels of the two 3'-UTR genotype groups either in cancer tissue $(\mathrm{p}=0.9418)$ or in normal tissue $(\mathrm{p}=0.33)$ (Table II).

TS mRNA expression level and prognosis. In the entire set of patients, no significant survival difference was observed between those who had higher TS mRNA level than the cut-off value (2.79) and those with low TS mRNA level $(\mathrm{p}=0.5103)$. For patients not receiving post-operative chemotherapy (5-FU-), the survival curves of high TS and low TS expressers were practically superimposable $(p=0.69)$, while 

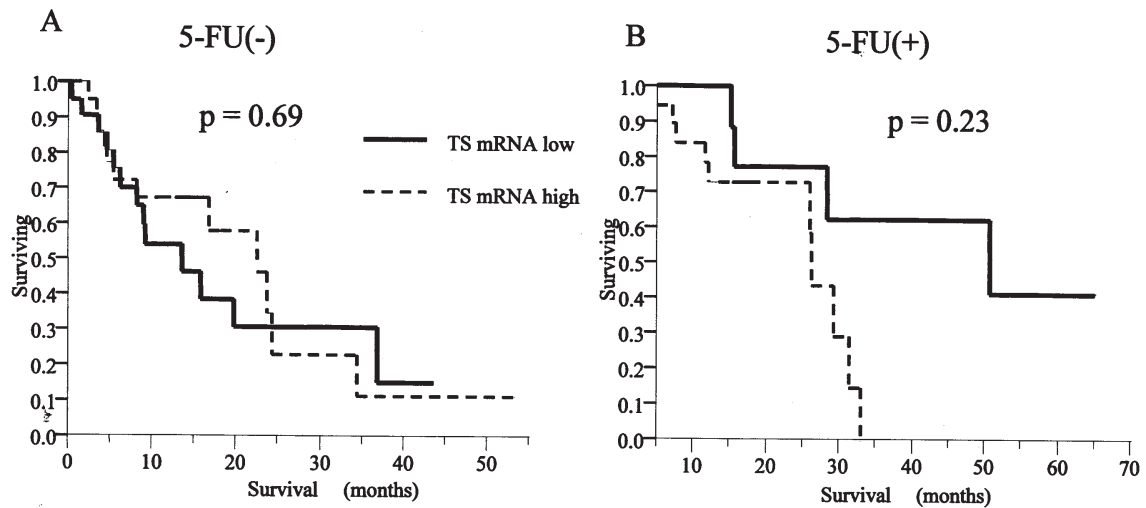

Figure 3. Kaplan-Meier analysis of overall survival in patients with esophageal adenocarcinoma according to TS mRNA expression levels. (A) In the patients who had received 5-FU related chemotherapy. (B) In the patients who had never received 5-FU.
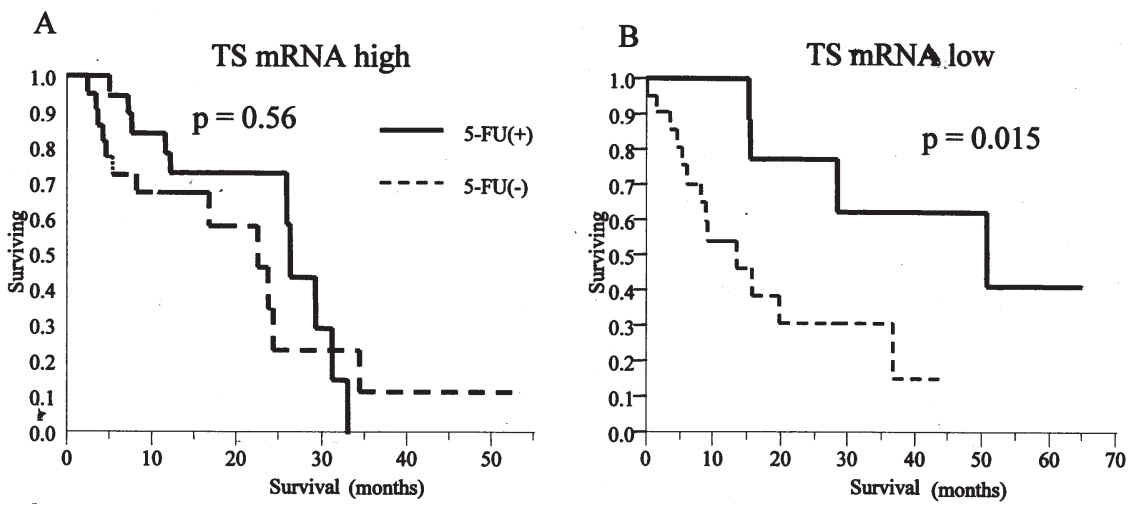

Figure 4. Kaplan-Meier analysis of overall survival in patients with esophageal adenocarcinoma according to a history of 5-FU treatment. (A) In patients with high TS mRNA levels. (B) In patients with low TS mRNA levels.
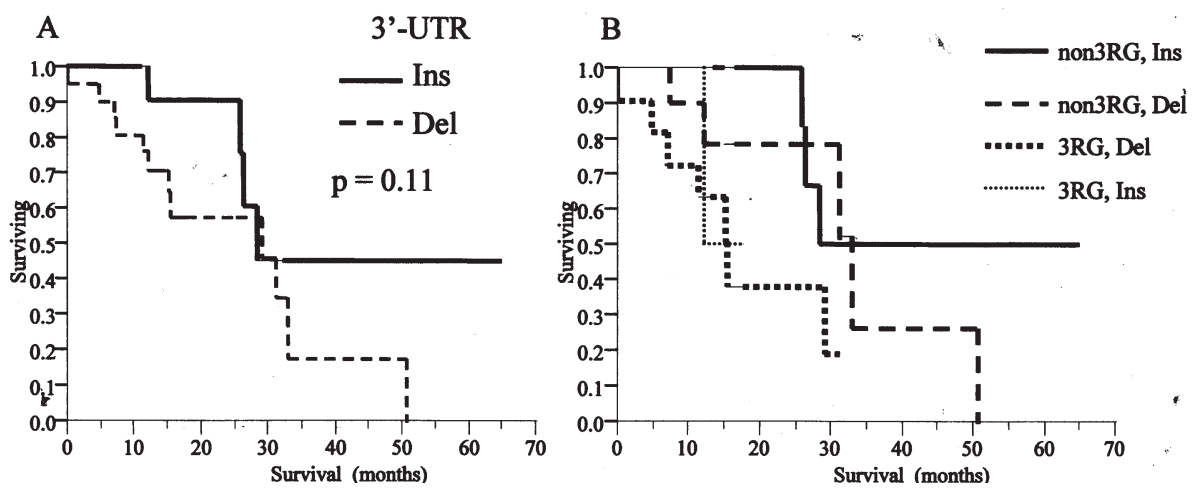

Figure 5. (A) Kaplan-Meier analysis of overall survival in patients with esophageal adenocarcinoma according to 3'-UTR polymorphism. 5'-UTR polymorphism was not taken into consideration. (B) Kaplan-Meier analysis of overall survival in patients with esophageal adenocarcinoma according to a combination of 5'-UTR and 3'-UTR polymorphism.

among 5-FU(+) patients, there was a trend toward better overall survival for low TS expressers compared to high expressers, although the difference did not reach significance $(p=0.23)$ (Fig. 3). However, when the patients were separated according to high and low TS expression, we found a significantly longer overall survival in the low TS-5-FU(+) group compared to the low TS-5-FU(-) group ( $\mathrm{p}=0.015$ ), while among patients with high TS mRNA, no survival difference was observed between 5-FU(+) patients and 5-FU(-) patients ( $\mathrm{p}=0.56$ ) (Fig. 4).
In the multivariate analysis, TS 5'-UTR genotype was significantly associated with survival when adjusting stage $(\mathrm{p}=0.033)$.

3'-UTR genotype and prognosis. We found an unequal distribution (linkage disequilibrium) of the 2 different 3'UTR genotypes between the 3RG and non-3RG 5'-UTR genotypes. Fig. 5A shows Kaplan-Meier survival curves of 3'-UTR Ins group and Del group among 5-FU received patients without sorting according to 5'UTR genotypes. 
Although there appears to be a trend of survival difference between the two groups, it may due to the fact that the Ins group is strongly associated with the non-3RG group. When we compared the association of 3'-UTR genotypes with overall survival within the same 5'-UTR groups (Fig. 5B), we observed no survival difference between 3'-UTR Ins genotypes and Del genotypes in either the combined group of patients $(\mathrm{p}=0.43$ within the $3 \mathrm{RG}$ group; $\mathrm{p}=0.28$ within non-3RG group) or in the $5-\mathrm{FU}(+)$ patients $(\mathrm{p}=0.78$ within the $3 \mathrm{RG}$ group; $\mathrm{p}=0.25$ within the non-3RG group).

\section{Discussion}

The goal of this study was to determine the interrelationships of 5'-UTR and 3'-UTR polymorphisms of the TS gene, TS gene expression and clinical outcome in esophageal cancer. In designing this study, we tried to avoid certain shortcomings apparent in some previous studies on this topic. First, in order to distinguish predictive from prognostic effects, we determined the association of these genetic factors with survival both in patients that had received 5-FUbased chemotherapy as well as patients that had not received chemotherapy. Secondly, we used microdissected tumor tissue to determine TS gene expression and polymorphism status because, as will be discussed below, tumor genotype in the case of heterozygous individuals may not reflect that in germ line tissue. Third, we analyzed TS polymorphisms at both the 5'UTR and 3'-UTR and thus we were able to assess the association of the 3'-UTR polymorphisms with outcome in the context of the same 5'-UTR groups.

Fig. 1 shows the non-3RG genotype to be significantly associated with better survival only in patients treated with 5-FU-based adjuvant chemotherapy (Fig. 1B) but not in the group of chemotherapy-untreated patients (Fig. 1A). The difference between these two profiles allows us to conclude that the non-3RG genotype is a predictive factor for 5-FU based therapy but not a prognostic factor, i.e., that the separation of the survival curves in Fig. 1B is due to the beneficial effects of the chemotherapy on non-3RG patients rather than intrinsically longer survival of such patients. The 3RG genotypes have been previously found to be significantly associated with worse response of gastric cancer treated with 5-FU-cisplatin (28) and worse prognosis for colorectal cancer patients treated adjuvantly with 5-FUbased therapy $(14,27)$. However, none of these studies specifically separated predictive and prognostic effects of the TS polymorphisms.

The data further show that, whereas chemotherapy produces a substantially and significantly better survival benefit for the non-3RG patients, 3RG patients receive no significant benefit from chemotherapy. Fig. 2, which is a re-plot of the survival data by genotype, shows a striking difference between the genotype groups in the divergence of the survival curves of chemotherapy-treated and untreated patients, especially at earlier time points. A similar result was previously observed in colorectal cancer patients (14).

The 5'-UTR genotypes are thought to influence 5-FUbased chemotherapy by regulating intratumoral TS levels. Several studies agree on the point that non-3RG genotype tumors have better response due to lower TS levels, but disagree as to the mechanism by which the 5'-UTR polymorphisms control TS expression. Mandola et al (15) and Morganti et al (29) reported that the 3RC genotype results in lower TS gene expression compared to $3 \mathrm{RG}$, whereas Kawakami and Watanabe (14) found no effect of the G-C SNP on TS gene expression but rather on TS protein expression. Our data show no relationship between TS mRNA levels and 5'-UTR genotype status and thus are more consistent with the hypothesis that the TS polymorphisms influence TS expression at the protein translation level. Another possibility is that differences in tumor response might arise from the effects of TS polymorphisms on folate levels. It has been known for some time that manipulations of intracellular folate pools can alter tumor sensitivity to $5-\mathrm{FU}(30,31)$ and there are a number of studies indicating a relationship between TS polymorphisms, circulating folate levels and cancer risk (32-34). However, to date we are aware of no published studies specifically addressing differences in folate levels between 3RG and non-3RG genotypes.

As many previous studies have, we also found an association between TS gene expression and clinical outcome. In general, low TS expression has predicted for better response to chemotherapy as well as better survival $(35,36)$, although there are several studies that seem to show the opposite relationship, i.e., that patients with higher intratumoral TS levels received more benefit from treatment $(37,38)$. This apparent contradiction in the effects of TS on tumor response has never really been explained satisfactorily (39). In theory as well as intuitively, it makes more sense that drug therapy directed at inhibition of TS should be more effective against tumors with lower TS expression. The results of the present study are consistent with this expectation in that 5-FU-based chemotherapy significantly increased survival of patients with low TS expression, whereas it had no effect on survival among patients with high TS mRNA levels. Moreover, our results also show that TS gene expression as a predictive factor for 5-FU-based therapy is independent of TS polymorphism status. Thus, patients who have both low TS mRNA and the non-3RG genotype represent a group that may derive the most benefit from chemotherapy, while those with high TS mRNA and 3RG genotype would be predicted to have the worst prognosis.

Previous studies have suggested that in addition to its role as the target for fluoropyrimidines, TS is also a prognostic factor in patients not treated with chemotherapy $(38,40,41)$ and it has even been suggested that TS is an oncogene (42). However, we saw no significant survival difference between the high and low TS expressers in the group of patients who had not received 5-FU chemotherapy. Thus, our data do not support the idea that in esophageal cancer the TS expression level in tumors is a prognostic marker independent of chemotherapy. Whether the discrepancy between our results and the earlier studies is due to patient selection, the tumor type or the precise mode of treatment is not clear at this time.

To better evaluate the prognostic and predictive roles of TS polymorphisms, we isolated genomic DNA from tumor tissues. The use of peripheral blood samples is a less invasive, more convenient and lower-cost method for obtaining DNA, but the problem is that the genotype of the germ-line tissue is not always the same as that of the cancer 
due to loss of heterozygosity ( $\mathrm{LOH}$ ) observed at the TS locus in chromosome $18 \mathrm{q}(43)$. $\mathrm{LOH}$ at the TS locus occurs at a frequency of $62-76 \%$ in colorectal cancer $(44,13)$ and $53 \%$ in esophageal adenocarcinoma (Kuramochi et al, Proc ASCO 22: abs. 842, 2000). An LOH event in the tumor cells of heterozygous $3 \mathrm{RG} / 2 \mathrm{R}$ individuals that resulted in loss of the $3 R G$ allele would confer a $2 \mathrm{R}$ genotype on the tumor, thereby changing the unfavorable prognosis indicated by the normal tissue genotype to a favorable one (13). In the present set of patients, LOH at the 5'-UTR locus of heterozygous patients led loss of the $3 R G$ allele in the tumor in only 3 cases. However, if these 3 patients are re-classified into the $3 R G$ group based on their normal tissue genotype (i.e., ignoring the $\mathrm{LOH}$ events in the tumors), the difference between the survival curves of the $3 R G$ and non-3RG groups is no longer statistically significant $(\mathrm{p}=0.2)$ (data not shown). This result again demonstrates the necessity for analyzing tumor genotype when studying relationships between TS polymorphisms and clinical end-points involving tumor response. Not doing so can at the least alter the true significance value of any findings from such studies and in some cases, may result in the reporting of significant relationships as non-significant.

Several previous studies have reported an association of the TS 3'-UTR polymorphism with prognosis $(18,19)$, whereas others observed no significant relationship (20-22). However, assigning a predictive or prognostic role to the 3'-UTR is complicated by linkage disequilibrium between the 5'-UTR and 3'-UTR polymorphisms $(17,22,45,46)$. In this study, we have shown a significantly frequent association of the non-3RG 5'-UTR genotype with the 3'-UTR Ins polymorphism. Thus, by identifying 3'-UTR Ins genotypes for study, we are also selecting for a predominantly non-3RG genotype in the 5'-UTR and cannot therefore with any certainty ascribe regulatory function to the 3'-UTR polymorphism. Our strategy for avoiding such ambiguities was to compare the effects of the 3'-UTR polymorphism on survival within the same 5'-UTR group. When we did this, there was no significant association between 3'-UTR polymorphism status and patients' prognosis.

In conclusion, 5'-UTR polymorphism status and TS mRNA levels are autonomous predictive factors for the effect of 5-FU based chemotherapy in esophageal cancer but are not prognostic factors independent of chemotherapy. Determining whether there is a $3 R G$ or non-3RG genotype in the 5'-UTR of TS together with TS mRNA expression may provide a clinically useful test for distinguishing patients who may benefit from 5-FU-based adjuvant therapy from those who would not benefit.

\section{Acknowledgements}

This study was supported by NIH grant RO1 CA84424. K.D. is CEO of Response Genetics Inc. K.D. and P.D. own stocks in Response Genetics Inc.

\section{References}

1. Spechler SJ and Goyal RK: The columnar-lined esophagus, intestinal metaplasia and Norman Barrett. Gastroenterology 110: 614-621, 1996.
2. Brenner B, Ilson DH and Minsky BD: Treatment of localized esophageal cancer. Semin Oncol 31: 554-565, 2004.

3. Kelsen D: Preoperative chemoradiotherapy for esophageal cancer. J Clin Oncol 19: 283-285, 2001.

4. Mooney MM: Neoadjuvant and adjuvant chemotherapy for esophageal adenocarcinoma. J Surg Oncol 92: 230-238, 2005.

5. Leichman CG, Lenz HJ, Leichman L, et al: Quantitation of intratumoral thymidylate synthase expression predicts for disseminated colorectal cancer response and resistance to protracted-infusion fluorouracil and weekly leucovorin. J Clin Oncol 15: 3223-3229, 1997.

6. Lenz HJ, Danenberg KD, Leichman CG, et al: p53 and thymidylate synthase expression in untreated stage II colon cancer: associations with recurrence, survival and site. Clin Cancer Res 4: 1227-1234, 1998.

7. Lenz HJ, Hayashi K, Salonga D, et al: p53 point mutations and thymidylate synthase messenger RNA levels in disseminated colorectal cancer: an analysis of response and survival. Clin Cancer Res 4: 1243-1250, 1998.

8. Salonga D, Danenberg KD, Johnson M, et al: Colorectal tumors responding to 5-fluorouracil have low gene expression levels of dihydropyrimidine dehydrogenase, thymidylate synthase and thymidine phosphorylase. Clin Cancer Res 6: 1322-1327, 2000.

9. Kaneda S, Takeishi K, Ayusawa D, Shimizu K, Seno T and Altman S: Role in translation of a triple tandemly repeated sequence in the 5'-untranslated region of human thymidylate synthase mRNA. Nucleic Acids Res 15: 1259-1270, 1987.

10. Kawakami K, Omura K, Kanehira E and Watanabe Y: Polymorphic tandem repeats in the thymidylate synthase gene is associated with its protein expression in human gastrointestinal cancers. Anticancer Res 19: 3249-3252, 1999.

11. Ishida Y, Kawakami K, Tanaka Y, Kanehira E, Omura K and Watanabe G: Association of thymidylate synthase gene polymorphism with its mRNA and protein expression and with prognosis in gastric cancer. Anticancer Res 22: 2805-2809, 2002.

12. Pullarkat ST, Stoehlmacher J, Ghaderi V, et al: Thymidylate synthase gene polymorphism determines response and toxicity of 5-FU chemotherapy. Pharmacogenomics J 1: 65-70, 2001.

13. Uchida K, Hayashi K, Kawakami K, et al: Loss of heterozygosity at the thymidylate synthase (TS) locus on chromosome 18 affects tumor response and survival in individuals heterozygous for a 28-bp polymorphism in the TS gene. Clin Cancer Res 10: 433-439, 2004.

14. Kawakami $\mathrm{K}$ and Watanabe G: Identification and functional analysis of single nucleotide polymorphism in the tandem repeat sequence of thymidylate synthase gene. Cancer Res 63: 6004-6007, 2003

15. Mandola MV, Stoehlmacher J, Muller-Weeks S, Cesarone G, $\mathrm{Yu}$ MC, Lenz HJ and Ladner RD: A novel single nucleotide polymorphism within the $5^{\prime}$ tandem repeat polymorphism of the thymidylate synthase gene abolishes USF-1 binding and alters transcriptional activity. Cancer Res 63: 2898-2904, 2003.

16. Ulrich CM, Bigler J, Velicer CM, Greene EA, Farin FM and Potter JD: Searching expressed sequence tag databases: discovery and confirmation of a common polymorphism in the thymidylate synthase gene. Cancer Epidemiol Biomarkers Prev 9: 1381-1385, 2000

17. Mandola MV, Stoehlmacher J, Zhang W, et al: A 6-bp polymorphism in the thymidylate synthase gene causes message instability and is associated with decreased intratumoral TS mRNA levels. Pharmacogenetics 14: 319-327, 2004.

18. Stoehlmacher J, Park DJ, Zhang W, Yang D, Groshen S, Zahedy S and Lenz HJ: A multivariate analysis of genomic polymorphisms: prediction of clinical outcome to 5-FU/ oxaliplatin combination chemotherapy in refractory colorectal cancer. Br J Cancer 91: 344-354, 2004.

19. Hitre E, Budai B, Adleff V, et al: Influence of thymidylate synthase gene polymorphisms on the survival of colorectal cancer patients receiving adjuvant 5-fluorouracil. Pharmacogenet Genomics 15: 723-730, 2005.

20. Liao Z, Liu H, Swisher SG, et al: Polymorphism at the 3'-UTR of the thymidylate synthase gene: a potential predictor for outcomes in Caucasian patients with esophageal adenocarcinoma treated with preoperative chemoradiation. Int J Radiat Oncol Biol Phys 3: 700-708, 2006.

21. Krajinovic M, Costea I, Primeau M, Dulucq S and Moghrabi A: Combining several polymorphisms of thymidylate synthase gene for pharmacogenetic analysis. Pharmacogenomics J 5: 374-380, 2005. 
22. Lecomte T, Ferraz JM, Zinzindohoue F, et al: Thymidylate synthase gene polymorphism predicts toxicity in colorectal cancer patients receiving 5-fluorouracil-based chemotherapy. Clin Cancer Res 10: 5880-5888, 2004.

23. Kuramochi H, Hayashi K, Uchida K, et al: Vascular endothelial growth factor messenger RNA expression level is preserved in liver metastases compared with corresponding primary colorectal cancer. Clin Cancer Res 12: 29-33, 2006.

24. Lord RV, Salonga D, Danenberg KD, et al: Telomerase reverse transcriptase expression is increased early in the Barrett's metaplasia, dysplasia, adenocarcinoma sequence. J Gastrointest Surg 4: $135-142,2000$

25. Kuramochi H, Hayashi K, Uchida K, et al: 5-fluorouracilrelated gene expression levels in primary colorectal cancer and corresponding liver metastasis. Int J Cancer 119: 522-526, 2006.

26. Marcuello E, Altes A, Del Rio E, Cesar A, Menoyo A and Baiget M: Single nucleotide polymorphism in the $5^{\prime}$ tandem repeat sequences of thymidylate synthase gene predicts for response to fluorouracil-based chemotherapy in advanced colorectal cancer patients. Int J Cancer 112: 733-737, 2004.

27. Kawakami K, Graziano F, Watanabe G, et al: Prognostic role of thymidylate synthase polymorphisms in gastric cancer patients treated with surgery and adjuvant chemotherapy. Clin Cancer Res 11: 3778-3783, 2005.

28. Ruzzo A, Graziano F, Kawakami K, et al: Pharmacogenetic profiling and clinical outcome of patients with advanced gastric cancer treated with palliative chemotherapy. J Clin Oncol 24: 1883-1891, 2006.

29. Morganti M, Ciantelli M, Giglioni B, et al: Relationships between promoter polymorphisms in the thymidylate synthase gene and mRNA levels in colorectal cancers. Eur J Cancer 41: 2176-2183, 2005

30. Park JG, Collins JM, Gazdar AF, Allegra CJ, Steinberg SM, Greene RF and Kramer BS: Enhancement of fluorinated pyrimidine-induced cytotoxicity by leucovorin in human colorectal carcinoma cell lines. J Natl Cancer Inst 80: 1560-1564, 1988.

31. Sohn KJ, Croxford R, Yates Z, Lucock M and Kim YI: Effect of the methylenetetrahydrofolate reductase C677T polymorphism on chemosensitivity of colon and breast cancer cells to 5-fluorouracil and methotrexate. J Natl Cancer Inst 96: 134-144, 2004.

32. Ulrich CM, Curtin K, Potter JD, Bigler J, Caan B and Slattery ML: Polymorphisms in the reduced folate carrier, thymidylate synthase, or methionine synthase and risk of colon cancer. Cancer Epidemiol Biomarkers Prev 14: 2509-2516, 2005.

33. Chen J, Kyte C, Chan W, Wetmur JG, Fuchs CS and Giovannucci E: Polymorphism in the thymidylate synthase promoter enhancer region and risk of colorectal adenomas. Cancer Epidemiol Biomarkers Prev 13: 2247-2250, 2004.
34. Trinh BN, Ong CN, Coetzee GA, Yu MC and Laird PW: Thymidylate synthase: a novel genetic determinant of plasma homocysteine and folate levels. Hum Genet 111: 299-302, 2002.

35. Aschele C, Debernardis D, Casazza S, et al: Immunohistochemical quantitation of thymidylate synthase expression in colorectal cancer metastases predicts for clinical outcome to fluorouracil-based chemotherapy. J Clin Oncol 17: 1760-1770, 1999.

36. Clark JL, Berger SH, Mittelman A and Berger FG: Thymidylate synthase gene amplification in a colon tumor resistant to fluoropyrimidine chemotherapy. Cancer Treat Rep 71: 261-265, 1987.

37. Johnston PG, Fisher ER, Rockette HE, et al: The role of thymidylate synthase expression in prognosis and outcome of adjuvant chemotherapy in patients with rectal cancer. J Clin Oncol 12: 2640-2647, 1994.

38. Edler D, Glimelius B, Hallstrom M, et al: Thymidylate synthase expression in colorectal cancer: a prognostic and predictive marker of benefit from adjuvant fluorouracil-based chemotherapy. J Clin Oncol 20: 1721-1728, 2002.

39. Ahlgren JD: Thymidylate synthase in nodal metastases: prognostic for chemosensitivity but not for adjuvant therapy? J Clin Oncol 23: 5452-5454, 2005.

40. Popat S, Wort R and Houlston RS: Relationship between thymidylate synthase (TS) genotype and TS expression: a tissue microarray analysis of colorectal cancers. Int J Surg Pathol 13: 127-133, 2005.

41. Voeller D, Rahman L and Zajac-Kaye M: Elevated levels of thymidylate synthase linked to neoplastic transformation of mammalian cells. Cell Cycle 3: 1005-1007, 2004.

42. Rahman L, Voeller D, Rahman M, et al: Thymidylate synthase as an oncogene: a novel role for an essential DNA synthesis enzyme. Cancer Cell 5: 341-351, 2004.

43. Vogelstein B, Fearon ER, Kern SE, Hamilton SR, Preisinger AC, Nakamura Y and White R: Allelotype of colorectal carcinomas. Science 244: 207-211, 1989.

44. Kawakami K, Ishida Y, Danenberg KD, Omura K, Watanabe G and Danenberg PV: Functional polymorphism of the thymidylate synthase gene in colorectal cancer accompanied by frequent loss of heterozygosity. Jpn J Cancer Res 93: 1221-1229, 2002.

45. Adleff V, Hitre E, Koves I, Orosz Z, Hajnal A and Kralovanszky J: Heterozygote deficiency in thymidylate synthase enhancer region polymorphism genotype distribution in Hungarian colorectal cancer patients. Int J Cancer 108: 852-856, 2004.

46. Graziano F, Kawakami K, Watanabe G, et al: Association of thymidylate synthase polymorphisms with gastric cancer susceptibility. Int J Cancer 112: 1010-1014, 2004. 